\title{
The activation of antioxidant and apoptosis pathways involved in damage of human proximal tubule epithelial cells by $\mathrm{PM}_{2.5}$ exposure
}

\author{
Xiaoliu Huang 1,2,3 , Xiujuan Shi ${ }^{3}$, Ji Zhou ${ }^{5}$, Sen Li ${ }^{1,3,4}$, Lijuan Zhang ${ }^{1,3,4}$, Huijun Zhao ${ }^{6}$, Xingya Kuang ${ }^{6 *}$
} and Jue $\mathrm{Li}^{1,3,4^{*}}$ (D)

\begin{abstract}
Background: Exposure to airborne fine particulate matter $\left(\mathrm{PM}_{2.5}\right)$ has been reported to be harmful to the human kidney. However, whether the activation of oxidative stress and cell apoptosis plays key roles in the nephrotoxicity caused by $\mathrm{PM}_{2.5}$ exposure is still poorly understood. The aim of this study was to explore the mechanism of cytotoxicity after $\mathrm{PM}_{2.5}$ exposure in human proximal tubule epithelial cells (HK-2 cells).

Results: $\mathrm{PM}_{2.5}$ exposure resulted in a significant decrease in cell viability, with an increase in LDH release and the early kidney damage marker kidney injury molecule-1 (KIM-1) expression in a dose-dependent manner and timedependent manner. $\mathrm{PM}_{2.5}$ exposure induced reactive oxygen species (ROS) generation and markedly elevated apoptosis in $\mathrm{HK}-2$ cells. In addition, $\mathrm{PM}_{2.5}$ exposure resulted in the activation of antioxidant pathway, as evidenced by the increased expressions of $\mathrm{Nrf2}, \mathrm{HO}-1$ and NQO1 and decreased expression of Keap1. Moreover, $\mathrm{PM}_{2.5}$ exposure also induced the activation of apoptotic pathway, as evidenced by the increased expressions of pro-apoptotic proteins Bax, caspase-3 and caspase-8 and decreased expression of antiapoptotic protein Bcl-2.

Conclusions: Our results demonstrated that both antioxidant pathway and apoptotic pathway played critical roles in the damage mediated by $\mathrm{PM}_{2.5}$ in HK-2 cells. This study would give us a strategy to prevent the impairment of renal function by $\mathrm{PM}_{2.5}$ induced through repression of oxidative stress and apoptosis.
\end{abstract}

Keywords: Fine particulate matter, Human proximal tubule epithelial cells, Cytotoxicity, Oxidative stress, Antioxidant pathway, Apoptosis pathway

\section{Background}

In recent years, the potential adverse effects of ambient fine particulate matter $\left(\mathrm{PM}_{2.5}\right.$, aerodynamic diameter $\leq 2.5 \mu \mathrm{m})$ on public health have caused significant concerns worldwide. The Global Burden of Disease

\footnotetext{
*Correspondence: 1400384@tongji.edu.cn; jueli1959@163.com

1 Shanghai East Hospital, Tongji University School of Medicine,

Shanghai 200092, China

${ }^{6}$ Department of Occupational Medicine, Yangpu Hospital, Tongji

University, Shanghai 200092, China

Full list of author information is available at the end of the article
}

(GBD) assessment showed that approximately 4.24 million premature deaths around the world were attributable to $\mathrm{PM}_{2.5}$ in 2015 [1]. $\mathrm{PM}_{2.5}$ is associated with greater toxicity than other airborne pollutants due to its small molecular diameter and large surface area, which make $\mathrm{PM}_{2.5}$ more likely than other pollutants to penetrate deep into alveoli and enter the blood circulation [2]. The nanoscale particles, often containing large amounts of toxic compounds such as metals and hydrocarbons, can also exert direct or indirect toxicity toward extrapulmonary organs such as the kidneys [3, 4]. Recently, 
some epidemiological studies have reported a strong and consistent association between $\mathrm{PM}_{2.5}$ exposure and reduced kidney function as well as an increased rate of renal function decline [5-7]. Studies have also shown that mid-/long-term exposure to high levels of $\mathrm{PM}_{2.5}$ can induce kidney damage in rodents $[8,9]$. However, the mechanism of $\mathrm{PM}_{2.5}$-induced renal dysfunction remains unclear.

Excessive generation of ROS and ensuing oxidative damage has been implicated in human or animal cells exposed to $\mathrm{PM}_{2.5}$ [10-12]. ROS is composed of superoxide anion radical, hydroxyl radical, peroxy radicals and nitric oxide radicals, etc. Oxidative stress occurs due to imbalance between the generation of ROS and the activity of antioxidants. Accumulating evidence has demonstrated that $\mathrm{PM}_{2.5}$-induced oxidative stress is a key molecular mechanism of $\mathrm{PM}_{2.5}$-triggered cytotoxicity [13-15]. Nuclear factor NF-E2-related factor-2 (Nrf2) is a basic region-leucine zipper (bZip) transcription factor which plays an important role in protecting against chemically induced oxidative stress and restoring cellular redox balance [16]. Over 200 cytoprotective proteins encoded by Nrf2 target genes have been demonstrated to be able to neutralize or detoxify both endogenous metabolites and environmental toxins [17]. Nrf2 functions when released from its redox-sensitive companion protein Keap1 (Kelch-like ECH-associated protein 1) upon detection of cytoplasmic oxidative stress [18]. After translocation into the nucleus, Nrf2 stimulates the transcription of genes encoding numerous detoxifying and antioxidant enzymes, such as NADPH: quinone oxidoreductase 1 (NQO-1) and heme oxygenase-1 (HO-1) [19].

In general, the harmful effects of reactive oxygen species on cells are mainly composed of DNA damage, lipid peroxidation and protein oxidation [20]. Overproduction of ROS induced by $\mathrm{PM}_{2.5}$ exposure has been associated with cell homeostasis imbalance, mitochondrial damage and apoptosis [21, 22]. Activation of apoptosis pathways, consisting of receptor-mediated (extrinsic) and mitochondrial (intrinsic) pathways, is a key step in apoptosis $[23,24]$. The death receptor pathway is characterized by TNF- $\alpha$-induced apoptosis and recruitment of caspase family proteins including caspase- 8 and caspase-3 [20]. The mitochondrial pathway is triggered by the release of cytochrome- $C$ from mitochondria, resulting in activation of caspase family proteins including caspase-3 [25]. During this process, early apoptosis is characterized by a decline in mitochondrial membrane potential (MMP) and by activation of Bcl-2 family members [26]. The cytotoxic effects of $\mathrm{PM}_{2.5}$ exposure that result in apoptosis of various cell types have been widely documented [21, 27]. However, there has been no report on the toxicity of $\mathrm{PM}_{2.5}$ to human proximal tubule epithelial cells via activation of antioxidant and apoptosis signaling pathways.

In this study, we chose human proximal tubule epithelial cell as a vitro model to investigate these signaling pathways triggered by $\mathrm{PM}_{2.5}$. The human kidney cell line HK-2 was first established in 1994 by Dr. Ryan's laboratory and has been widely used in experiments on nephrology and nephrotoxicity [12, 28, 29]. Moreover, HK-2 cells have been found to exhibit most of the functional characteristics of proximal tubular tissues in human kidneys [30-32]. However, the cytotoxicity induced by $\mathrm{PM}_{2.5}$ in HK-2 cells has not been reported at present. Here, our findings would provide important insights into the involvement of $\mathrm{PM}_{2.5}$ pollution in kidney damage.

\section{Materials and methods}

\section{Sampling and preparation}

$\mathrm{PM}_{2.5}$ samples were continuously collected from Changji Road, Shanghai, China, between January and February 2018. The sampling site was located at Anting Hospital, Jiading District, in close proximity to a busy street with high traffic and commercial activity. There were also several large automobile factories and small industrial plants in the surrounding area. The sampling inlet was installed on the roof top of a hospital building, $15 \mathrm{~m}$ above the ground. $\mathrm{PM}_{2.5}$ samples were trapped on Whatman (Mainstone, UK) glass filters (203 $\mathrm{mm} * 254 \mathrm{~mm})$ using a $\mathrm{PM}_{2.5}$ large-volume air sampler $\left(1.05 \mathrm{~m}^{3} / \mathrm{min}\right.$, Qingdao Jinshida KB-1000, China) for $24 \mathrm{~h}$. The filters were equilibrated at $30 \%$ relative humidity and room temperature $\left(25^{\circ} \mathrm{C}\right)$ for $48 \mathrm{~h}$ prior to and immediately following sampling and subsequently weighed using a high-precision microbalance (Liangping FA1004, China) to measure the mass of the collected $\mathrm{PM}_{2.5}$. All sampled filters were stored in the dark at $-20^{\circ} \mathrm{C}$ until further analysis.

The collected filters were cut into small pieces and sonicated in ultrapure water for $3 \mathrm{~h}(6 * 30 \mathrm{~min})$. Then, the filters were removed, and the extracted solution was filtered through 12 layers of sterile gauze. The solution was then collected in a pre-weighed sterile $50-\mathrm{mL}$ tube, freeze-dried in a vacuum and re-weighed to determine the mass of extracted particles. The extracted particles were then suspended in PBS buffer at $5 \mathrm{mg} / \mathrm{mL}$ and stored at $-80{ }^{\circ} \mathrm{C}$ until further treatment or chemical characterization analysis.

\section{$\mathrm{PM}_{2.5}$ chemical characterization}

Metal elements and polycyclic aromatic hydrocarbons (PAHs) were detected in the extracted $\mathrm{PM}_{2.5}$ samples. PAHs were measured using a thermal desorption at $300{ }^{\circ} \mathrm{C}$ coupled with cold trapping, and the samples were subsequently freeze-dried into powder and measured using gas chromatography-mass spectrometry (GC/MS) 
analyses (Trace DSQII-MS, Thermo Fisher, USA). For detection of metal elements, $\mathrm{PM}_{2.5}$ samples were digested using $10 \mathrm{~mL}$ of a mixed solution of $\mathrm{HNO}_{3}$ and $\mathrm{HCl}(1: 3$ $v / v)$ in $50 \mathrm{~mL}$ of polytetrafluoroethylene (PTFE) and subsequently measured using inductively coupled plasma mass spectrometry (ICP-MS7700, Agilent, USA).

\section{Cell culture and $\mathrm{PM}_{2.5}$ exposure}

Human proximal tubule epithelial cells (provided kindly by Professor Andong Qiu, School of Life Sciences and Technology, Tongji University, Shanghai, China) were cultured in DMEM/F12 (Biological Industries, Israel) supplemented with $10 \%(v / v)$ fetal bovine serum (Gibco, Grand Island, NY) and 1\% $(v / v)$ penicillin/streptomycin (Solarbio, China). Exponentially growing cells were maintained at $37{ }^{\circ} \mathrm{C}$ in a humidified incubator containing $5 \%$ $\mathrm{CO}_{2}$, with daily replacement of the cell culture medium. Cells were washed with phosphate-buffered saline (PBS), digested with $0.25 \%$ trypsin (Solarbio, China) and seeded in new culture flasks/dishes after they reached $80 \%$ confluence. $\mathrm{PM}_{2.5}$ samples were sonicated for $10 \mathrm{~min}$ prior to cell treatment. Cells were starved using DMEM/F12 medium containing $0.1 \%$ FBS for $2 \mathrm{~h}$ and then exposed to $\mathrm{PM}_{2.5}$ in DMEM/F12 using a series of concentrations in the indicated time.

\section{Cytotoxicity assay}

Cell viability was assessed using a CCK-8 assay kit (Sangon Biotech, China) according to the manufacturer's instructions. Briefly, cells $\left(1 \times 10^{4}\right)$ per well were seeded in 96-well plates and treated with the indicated concentrations of $\mathrm{PM}_{2.5}(0-400 \mu \mathrm{g} / \mathrm{mL})$ in $0.1 \mathrm{~mL}$ cell medium for $24 \mathrm{~h}$. Next, the $\mathrm{PM}_{2.5}$ suspension was replaced with an equal volume of fresh medium containing $10 \mu \mathrm{L}$ of CCK- 8 solution, and the cells were incubated for $2-4 \mathrm{~h}$ at $37{ }^{\circ} \mathrm{C}$. The resulting absorbance was determined at $450 \mathrm{~nm}$ on a microplate reader (Waltham, MA, USA). LDH is a stable enzyme that exists in the cytoplasm of all cells and is rapidly released into the culture supernatant when the plasma membrane is damaged. LDH activity in the supernatant was determined using a LDH assay kit (Beyotime, China) according to the manufacturer's instructions after incubation for $24 \mathrm{~h}$ with different concentrations of $\mathrm{PM}_{2.5}$.

\section{Apoptosis assay}

Apoptotic morphological changes in the nuclear chromatin of cells were detected using Hoechst 33342 staining (Beyotime, China). HK-2 cells $\left(1 \times 10^{5}\right.$ cells $)$ were seeded in 12-well plates and treated with the indicated concentrations of $\mathrm{PM}_{2.5}$ or vehicle for $24 \mathrm{~h}$. The cells were incubated with Hoechst 33342 Detection Kit reagents according to the manufacturer's protocol. After staining, the cells were washed with PBS for 3 times and immediately visualized under a fluorescence microscope (Olympus, Japan).

Apoptosis was measured by Annexin V-FITC staining and PI labeling (Multi-sciences, China). To quantify apoptosis, harvested cells were washed twice with ice-cold PBS and then resuspended in $0.5 \mathrm{~mL}$ of binding buffer at a concentration of $1 \times 10^{5}$ cells $/ \mathrm{mL}$. Next, $5 \mu \mathrm{L}$ of Annexin V-FITC and $10 \mu \mathrm{L}$ of PI were added to these cells, which were kept in the dark at room temperature for $5 \mathrm{~min}$. Data acquisition was performed using a BD Biosciences FACSCalibur flow cytometer (Franklin Lakes, NJ, USA), and the data were analyzed using CellQuest software (BD Biosciences, Franklin Lakes, NJ). The results are presented as the percentages of cells in both early and advanced apoptosis.

\section{ROS assay}

Intracellular production of ROS was determined using the cell-permeable probe DCFH-DA (Beyotime, China), which preferentially binds to peroxides. Briefly, HK-2 cells were pretreated with the indicated concentrations of $\mathrm{PM}_{2.5}$ for $6 \mathrm{~h}$, then collected and treated with serum-free medium containing $10 \mu \mathrm{M}$ DCFH-DA for $30 \mathrm{~min}$ at $37^{\circ} \mathrm{C}$ in the dark. The cells were washed 3 times with DMEM/ F12 or PBS, and the fluorescence intensity was immediately measured using fluorescence microscopy and flow cytometry.

\section{Measurement of MMP}

A total of $3 \times 10^{5}$ cells were seeded in 6-well plates and exposed to different concentrations of $\mathrm{PM}_{2.5}$ for $24 \mathrm{~h}$. Cells were subsequently collected and washed twice with ice-cold PBS and then incubated in fresh medium containing various concentrations of JC-1 (Beyotime, China) for $30 \mathrm{~min}$ at $37^{\circ} \mathrm{C}$. Cells were then washed three times and used for the detection of green (monomer) and red (aggregate) fluorescence. The intensity of fluorescence was measured using a multi-well plate reader (Waltham, MA, USA) at various intensities (red: excitation/emission 535/590 nm, green: excitation/emission 485/535 nm). Results were expressed as the amount of red fluorescence/green fluorescence.

\section{Transmission electron microscopy}

Ultrastructure of $\mathrm{HK}-2$ cells after $\mathrm{PM}_{2.5}$ exposure was performed using TEM analysis as described in the previous study [33]. First, treated cells were harvested and immediately fixed in $2.5 \%$ glutaraldehyde overnight at $4{ }^{\circ} \mathrm{C}$, then washed 3 times with $0.1 \mathrm{M}$ PBS and underwent $2 \mathrm{~h}$ post-fixation in osmic acid at room temperature. Subsequently, cells were washed 3 times with $0.1 \mathrm{M} \mathrm{PBS}$, then dehydrated in a graded alcohol series $(30 \%, 50 \%$, 
$70 \%, 80 \%, 85 \%, 90 \%, 95 \%$ and $100 \%)$ and embedded in epoxy resin. Then, ultrathin serial sections $(60-100 \mathrm{~nm})$ of embedded samples were cut using ultramicrotomy (Leica, EM UC7, Germany), then stained with uranyl acetate and lead citrate and examined under an electron microscope (Tecnai G 20 TWIN, FEI Company, USA) at $200 \mathrm{kv}$.

\section{Western blot analysis}

After exposure to $\mathrm{PM}_{2.5}, \mathrm{HK}-2$ cells were separated from the culture medium and lysed in ice-cold NP40 buffer (Beyotime, China) containing protease and phosphatase inhibitors. Then, the liquid supernatants were collected by centrifugation at $12,000 \times g$ for $15 \mathrm{~min}$ at $4{ }^{\circ} \mathrm{C}$, and the protein concentrations were calculated using a BCA protein quantitation kit (Beyotime, China). The protein samples were subjected to $10 \%$ or $15 \%$ sodium dodecyl sulfate-polyacrylamide gel electrophoresis (SDS-PAGE) and transferred onto polyvinylidene difluoride (PVDF) membranes (Millipore, MA, USA). The PVDF membranes were then blocked in 5\% non-fat milk at room temperature for $1 \mathrm{~h}$, incubated with specific primary antibodies KIM-1 (Cell Signaling Technology, USA), Bax, Bcl-2, caspase-8, caspase-3, Nrf2, Keap1, NQO1, HO-1, GAPDH and $\beta$-actin (Proteintech, USA) at $4{ }^{\circ} \mathrm{C}$ overnight and subsequently incubated with HRP-conjugated secondary antibodies (Proteintech, USA) at room temperature for $1 \mathrm{~h}$. After washing with TBST, the protein bands were visualized using an enhanced chemiluminescence system (Image Quant LAS, 4000 mini). Protein expression was quantified using ImageJ software (version 1.4.2b, USA) and standardized to the expression of a housekeeping gene ( $\beta$-actin or GAPDH) and is expressed as the fold change compared to that in the control samples.

\section{Statistical analysis}

Data were expressed as mean \pm standard deviation (SD). Statistical analyses were performed using SPSS Statistical 19.0 (IBM, USA) by analysis of variance with Dunnet's least significant difference post hoc tests for multiple group comparison. $p<0.05$ indicated statistical significance.

\section{Results}

\section{Major chemical components in $\mathrm{PM}_{\mathbf{2 . 5}}$ samples}

Table 1 shows the chemical compositions detected in the collected $\mathrm{PM}_{2.5}$. The list of organic components showed that chrysene, benzo[b]fluoranthene, benzo[k]fluoranthene, acenaphthylene and benzo[g,h,i]perylene were the dominant PAHs present in $\mathrm{PM}_{2.5}$. Among the 21 metal elements measured, there were both natural environment-related elements (i.e., $\mathrm{Ti}, \mathrm{Al}, \mathrm{Zn}, \mathrm{Fe}$, etc.) and anthropogenic elements (i.e., $\mathrm{Pb}, \mathrm{Mn}, \mathrm{Ni}, \mathrm{Cd}, \mathrm{Cu}$, etc.).
Table 1 Chemical compositions detected in $\mathbf{P M}_{2.5}$

\begin{tabular}{|c|c|c|c|}
\hline \multicolumn{2}{|c|}{ Inorganic components } & \multicolumn{2}{|l|}{ Organic components } \\
\hline Metal & $\begin{array}{l}\text { Concentration } \\
(\mu \mathrm{g} / \mathrm{g})\end{array}$ & PAH & $\begin{array}{l}\text { Concentration } \\
\text { (ng/g) }\end{array}$ \\
\hline $\mathrm{Be}$ & 0.343 & Naphthalene & 75.285 \\
\hline B & 263.538 & Acenaphthylene & 923.445 \\
\hline $\mathrm{Al}$ & 1028.309 & Acenaphthene & 21.214 \\
\hline $\mathrm{Ti}$ & 46.822 & Fluorene & 31.340 \\
\hline V & 22.985 & Phenanthrene & 200.969 \\
\hline $\mathrm{Cr}$ & 68.365 & Anthracene & 21.593 \\
\hline $\mathrm{Mn}$ & 352.490 & Fluoranthene & 255.026 \\
\hline $\mathrm{Fe}$ & 3176.148 & Pyrene & 125.720 \\
\hline $\mathrm{Co}$ & 4.881 & Benzo(a)anthracene & 299.631 \\
\hline $\mathrm{Ni}$ & 34.913 & Chrysene & 1583.644 \\
\hline $\mathrm{Cu}$ & 140.723 & Benzo[b]fluoranthene & 1161.528 \\
\hline $\mathrm{Zn}$ & 2938.283 & Benzo[k]fluoranthene & 1034.071 \\
\hline As & 49.031 & Benzo[a]pyrene & 389.603 \\
\hline Se & 39.217 & Dibenzo(a,h)anthracene & 130.953 \\
\hline Mo & 19.125 & Benzo[g,h,i]perylene & 885.796 \\
\hline $\mathrm{Ag}$ & 1.639 & Indeno(1,2,3-cd)pyrene & 468.698 \\
\hline $\mathrm{Cd}$ & 9.964 & & \\
\hline $\mathrm{Sb}$ & 25.977 & & \\
\hline $\mathrm{Ba}$ & 83.211 & & \\
\hline $\mathrm{TI}$ & 3.101 & & \\
\hline $\mathrm{Pb}$ & 280.036 & & \\
\hline
\end{tabular}

$\mathrm{Al}, \mathrm{Mn}, \mathrm{Fe}, \mathrm{Zn}, \mathrm{Pb}$ and $\mathrm{B}$ were the most abundant elements in the $\mathrm{PM}_{2.5}$ samples.

\section{$\mathrm{PM}_{2.5}$ induces cell damage and cytotoxicity in HK-2 cells}

HK-2 cells were exposed to various concentrations $(0-400 \mu \mathrm{g} / \mathrm{mL})$ of $\mathrm{PM}_{2.5}$ for $24 \mathrm{~h}$. Following treatment with $\mathrm{PM}_{2.5}$, there was a gradual change in HK-2 cell shape from tiled to round, along with obvious shrinkage and destruction of intercellular junctions, especially at higher concentrations of $\mathrm{PM}_{2.5}$ (100, 200 or $400 \mu \mathrm{g} / \mathrm{mL}$ ) (Fig. 1a). We further performed CCK-8 assay to investigate the cytotoxicity of $\mathrm{PM}_{2.5}$ on $\mathrm{HK}-2$ cells. Treatment using $\mathrm{PM}_{2.5}$ with a concentration of $50 \mu \mathrm{g} / \mathrm{mL}$ or higher significantly induced cytotoxicity in HK-2 cells (Fig. 1b). Moreover, the cytotoxicity of $\mathrm{PM}_{2.5}$ on $\mathrm{HK}-2$ cells increased with elevating concentrations of $\mathrm{PM}_{2.5}$, demonstrating a clear dose-effect relationship. We then examined the cytotoxicity of $\mathrm{PM}_{2.5}$ in $\mathrm{HK}-2$ cells using $\mathrm{LDH}$ release assay. The level of $\mathrm{LDH}$ released from $\mathrm{PM}_{2.5}$-treated $\mathrm{HK}-2$ cells was significantly increased following 24-h exposure compared to untreated control cells, in a dose-dependent manner (Fig. 1c). In order to determine whether $\mathrm{PM}_{2.5}$ could induce kidney damage, we examined the protein expression of kidney injury molecule-1 (KIM-1), an early molecular biomarker, to establish kidney dysfunction. 


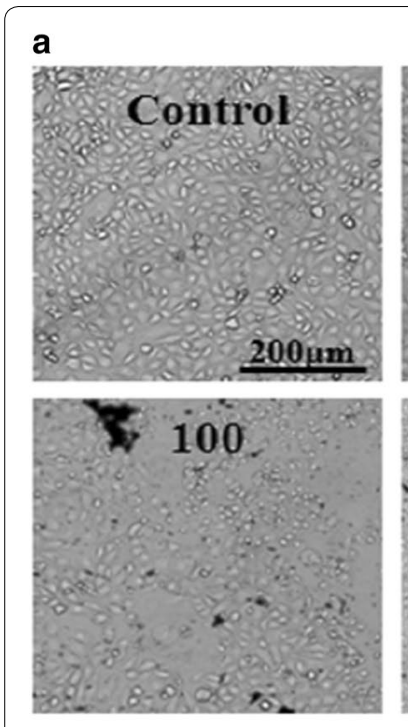

C

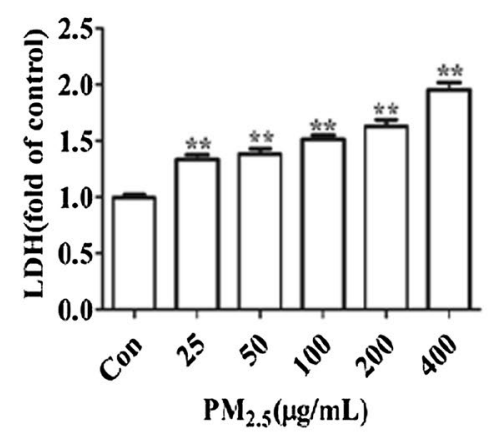

d
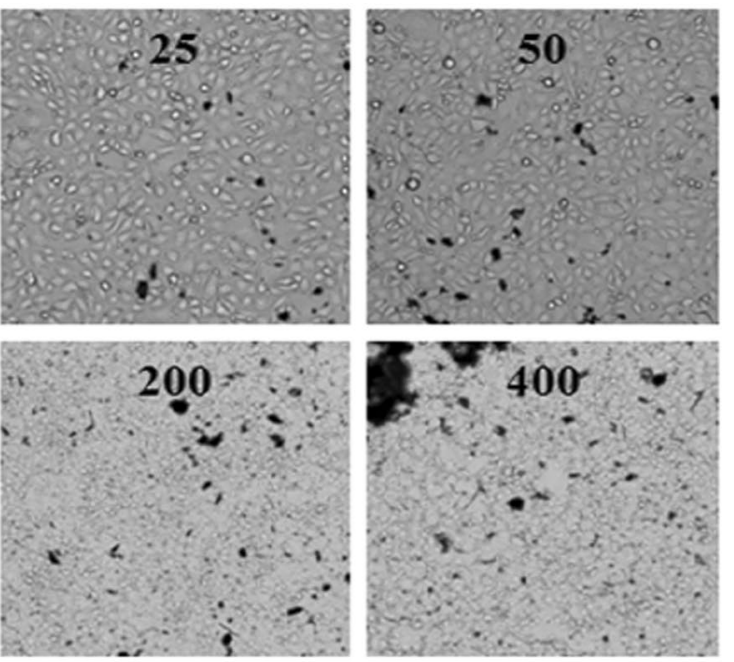

$\mu \mathrm{g} / \mathrm{mL}$ b



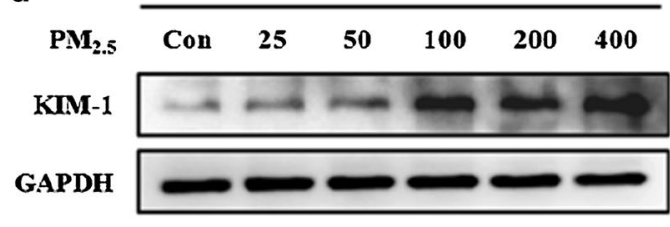

$200 \mu \mathrm{g} / \mathrm{mL} \mathrm{PM}_{2.5}$, Time(h)

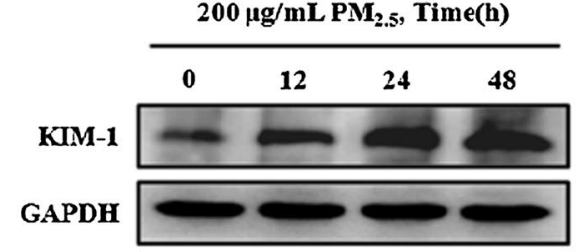

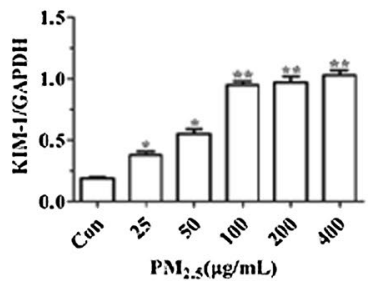

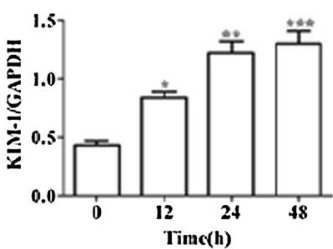

Fig. $1 \mathrm{PM}_{2.5}$ induces cell damage and cytotoxicity in HK-2 cells. a Representative images showing the morphology of HK-2 cells treated with PM 2.5 $(0-400 \mu \mathrm{g} / \mathrm{mL})$ for $24 \mathrm{~h}$ as observed using an optical microscope. $\mathbf{b}$ Cell viability of HK-2 cells was measured using CCK-8 assay. $\mathbf{c}$ LDH release, HK-2 cells were treated with $25,50,100,200$ or $400 \mu \mathrm{g} / \mathrm{mL}$ of PM 2.5 for $24 \mathrm{~h}$. d Western blot analysis of the expressions of indicated protein (KIM-1) in HK-2 cells after treatment with different concentrations of $\mathrm{PM}_{2.5}$ for $24 \mathrm{~h}$, or at varying time intervals using $200 \mu \mathrm{g} / \mathrm{mL}$ of PM 2.5 . Intensity of protein bands was quantified using ImageJ software and normalized to that of GAPDH. ${ }^{*} p<0.05,{ }^{* *} p<0.01$ and ${ }^{* * *} p<0.001$ vs. control or $0 \mathrm{~h}$

Western blot analysis demonstrated that treatment with $\mathrm{PM}_{2.5}$ significantly increased the expression of KIM-1 in both a dose- and time-dependent manner (Fig. 1d). Taken together, these results showed that $\mathrm{PM}_{2.5}$ exposure significantly induced cytotoxicity and cell damage in HK-2 cells.

\section{Mitochondria and DNA damage detection}

To investigate the type of cell death induced by $\mathrm{PM}_{2.5}$ treatment in HK-2 cells, we examined the nuclear morphology of dying cells using a fluorescent DNA-binding dye, Hoechst 33342. $\mathrm{PM}_{2.5}$ exposure for $24 \mathrm{~h}$ resulted in distinctive apoptotic morphological changes in HK-2 cells, such as cell shrinkage, chromatin condensation and nuclear fragmentation, as indicated by the red arrows (Fig. 2a). We also examined the morphological changes of mitochondria in HK-2 cells following treatment with $\mathrm{PM}_{2.5}$ using TEM. Untreated control HK-2 cells presented regular or oval-shaped mitochondria with numerous cristae that are uniformly distributed in the cytoplasm. In contrast, HK-2 cells that treated with $\mathrm{PM}_{2.5}(400 \mu \mathrm{g} / \mathrm{mL})$ displayed irregular shaped mitochondria with cristae disorder and mitochondrial membrane breach (Fig. 2b). We further performed JC-1 probe staining using multi-well plate reader to assess the effect of $\mathrm{PM}_{2.5}$ treatment on MMP. Untreated control HK-2 cells 




with functional mitochondria were stained with red JC-1 aggregates, while cells with impaired mitochondria were stained with green JC-1 monomers. Treatment of cells with $\mathrm{PM}_{2.5}$ resulted in a significant decrease in red fluorescence intensity coupled with an increase in green fluorescence intensity in a dose-dependent manner, which demonstrated that $\mathrm{PM}_{2.5}$ significantly decreased the MMP of HK-2 cells (Fig. 2c).

\section{Apoptosis ratio detection}

We further performed flow cytometry assay, which showed that $\mathrm{PM}_{2.5}$ treatment led to a significant apoptosis in HK-2 cells, compared with untreated control cells $(p<0.01)$. Moreover, the percentages of apoptotic cells were significantly increased at elevating levels of $\mathrm{PM}_{2.5}$ treatment, which demonstrated a clear dose-effect relationship. A peak apoptotic rate of $26.2 \%$ was observed at the highest concentration of $\mathrm{PM}_{2.5}$ treatment $400 \mu \mathrm{g} /$ $\mathrm{mL}$ (Fig. 3). These results indicated that the inhibition of $\mathrm{PM}_{2.5}$ on HK-2 cell proliferation was mainly attributed to the induction of cellular apoptosis.

Effect of $\mathrm{PM}_{2.5}$ on intracellular ROS levels

We next examined whether $\mathrm{PM}_{2.5}$ treatment induced intracellular ROS production. Treatment with $\mathrm{PM}_{2.5}$ significantly upregulated the production of intracellular 




b

\section{Annexin V FITC}

Fig. 3 Apoptosis of HK-2 cells after exposure to PM 2.5 for $24 \mathrm{~h}$. a Apoptosis was analyzed by FACS using Annexin V-FITC/PI apoptosis kits. $\mathbf{b}$ Representative results from three independent experiments. The data are presented as the mean \pm SD. ${ }^{*} p<0.05,{ }^{* *} p<0.01$ and ${ }^{* *} p<0.001$ compared with the control group

ROS in a dose-dependent manner in HK-2 cells (Fig. 4). DCFH-DA staining using fluorescence microscopy analysis showed that $\mathrm{PM}_{2.5}$ increased the intracellular green fluorescence intensity indicative of ROS accumulation, in a concentration-dependent manner. In addition, flow cytometry analysis showed that treatment with $\mathrm{PM}_{2.5}$ at 50, 100, 200 and $400 \mu \mathrm{g} / \mathrm{mL}$ significantly increased the mean fluorescence intensity compared to untreated control cells.

Increases in ROS have been shown to activate the redox-sensitive Nrf2/Keap1 signaling pathway, which plays a vital role in oxidative stress [17]. Thus, we determined the expressions of Nrf2, Keap1, HO-1 and NQO1 following $\mathrm{PM}_{2.5}$ exposure in $\mathrm{HK}-2$ cells using Western blot analyses. $\mathrm{PM}_{2.5}$ treatment resulted in a significant increase in the expressions of active $\mathrm{Nrf} 2, \mathrm{HO}-1$ and NQO1, in a dose- and time-dependent manner, whereas the expression of Keap1 was significantly decreased in HK-2 cells (Fig. 5). Collectively, these findings demonstrated that $\mathrm{PM}_{2.5}$ induced activation of the cascade of Nrf2, Keap1, HO-1 and NQO1 proteins involved in the oxidative stress response.

\section{$\mathrm{PM}_{2.5}$ induces the activation of apoptosis pathways}

In order to study whether $\mathrm{PM}_{2.5}$ treatment also induced the activation of apoptosis pathways, we examined the expressions of Bcl-2, Bax, caspase- 3 and caspase- 8 using Western blot analyses. $\mathrm{PM}_{2.5}$ treatment induced a significant increase in the expressions of the pro-apoptotic protein Bax and activated caspase- 3 and caspase- 8 in both a dose- and time-dependent manner, whereas the expression of $\mathrm{Bcl}-2$ was decreased at higher concentrations of $\mathrm{PM}_{2.5}$ or longer time in HK-2 cells (Fig. 6). Collectively, these findings indicated that $\mathrm{PM}_{2.5}$ induced the activation of the cascade of Bcl-2, Bax, caspase- 3 and caspase- 8 proteins involved in the cellular apoptosis pathway.

\section{Discussion}

$\mathrm{PM}_{2.5}$ containing complex chemical composition comes from both natural sources and anthropogenic emissions [34]. In urban areas, $\mathrm{PM}_{2.5}$ is mainly generated from anthropogenic sources including both primary and secondary particles. In this study, we analyzed $16 \mathrm{PAHs}$ and 21 metal elements in the $\mathrm{PM}_{2.5}$ particles collected from Shanghai. As shown in Table 1, chrysene was the most abundant $\mathrm{PAH}$, followed by benzo[b]fluoranthene, benzo[k]fluoranthene, acenaphthylene and benzo[g,h,i] perylene. This may be associated with the large number of restaurants and traffic vehicles near the sampling location. A previous study reported that coal combustion and vehicle sources were dominant PAHs sources in Shanghai urban soil [35]. Another study revealed that coal combustion and traffic emission contributed with $34.9 \%$ and $27.5 \%$, respectively, to the PAHs in $\mathrm{PM}_{2.5}$ collected from Shanghai [36]. Our results also showed that Fe was the highest level of the inorganic elements, followed by $\mathrm{Zn}$, $\mathrm{Al}, \mathrm{Mn}$ and $\mathrm{Pb}$. Fe and $\mathrm{Al}$ are crustal elements, while $\mathrm{Zn}$, 

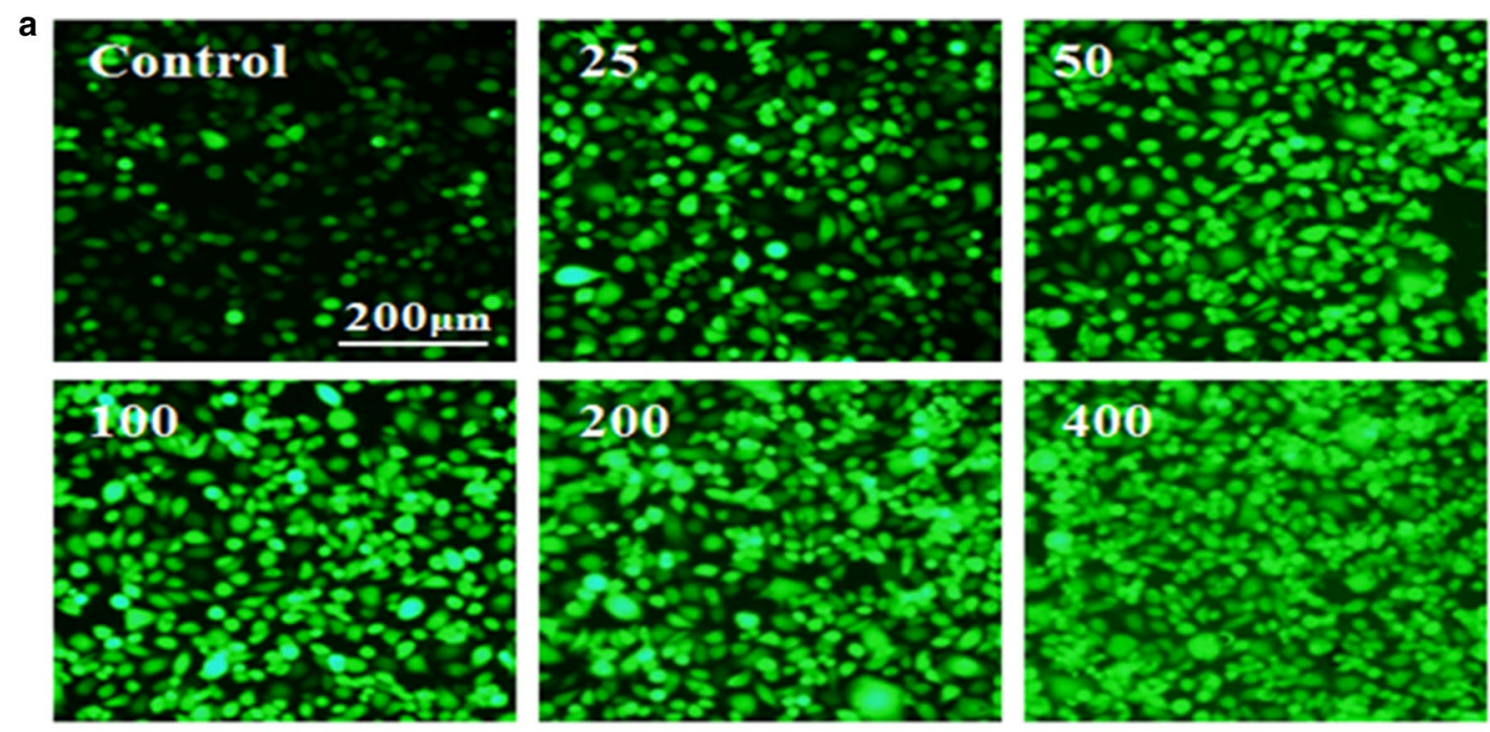

b
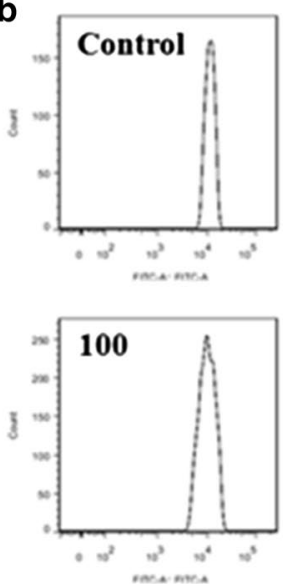



tenes nos.



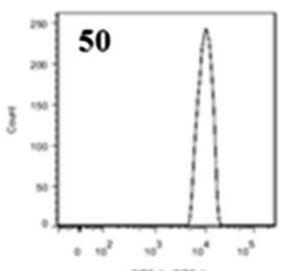



C

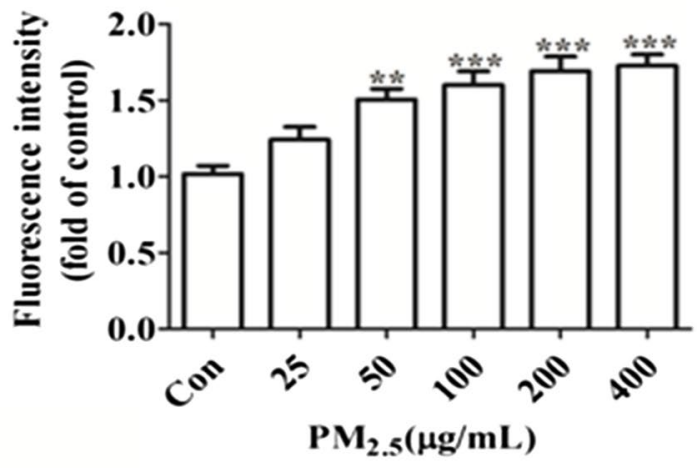

Fig. 4 Intracellular ROS overproduction following treatment with $\mathrm{PM}_{2.5}$ in HK-2 cells. a-c Intracellular levels of ROS were assessed using DCFH-DA staining followed by fluorescence microscopy and flow cytometry. Incubation with various concentrations of PM $2.5(0-400 \mu \mathrm{g} / \mathrm{mL})$ induced intracellular ROS overproduction in a dose-dependent manner. $\mathrm{PM}_{2.5}$ induces the activation of antioxidant pathway

$\mathrm{Mn}$ and $\mathrm{Pb}$ are trace elements. The presence of automobile factories and steel industries around the sampling site may be principal factors. All these results demonstrated that the collected $\mathrm{PM}_{2.5}$ samples mainly comprised a complex mixture of chemicals sourced from both natural and anthropogenic sources.

Diesel exhaust particles have been reported to be able to induce cytotoxicity in renal cell lines such as HEK-293. In the current study, we also found that $\mathrm{PM}_{2.5}$ induced damage in HK-2 cells. As shown in Fig. $1 \mathrm{a}, \mathrm{PM}_{2.5}$ treatment resulted in significant changes in cellular morphology in HK-2 cells, including increases in shape irregularity, cellular shrinkage, destruction of intercellular junctions and reductions in cell density, and these changes were especially pronounced at higher concentrations. Notably, cell viability assays are vital in determining the cellular response to a toxicant [37]. $\mathrm{PM}_{2.5}$ particles are commonly thought to have significant impacts on genotoxicity and cytotoxicity as well as on cell proliferation. Our current study showed that $\mathrm{PM}_{2.5}$ could significantly decrease cell viability and increase the release of $\mathrm{LDH}$, a marker of cell membrane damage, in HK-2 cells in a dose-dependent manner, consistent with the results of similar studies in other cell lines [38, 39]. Kidney injury molecule-1 (KIM1 ) is a type 1 transmembrane glycoprotein and potential biomarker for the detection of tubular injury in renal diseases [40]. It was reported that the expression of KIM-1 protein in the kidney cortex of the $\mathrm{PM}_{2.5}$-exposed group 



b
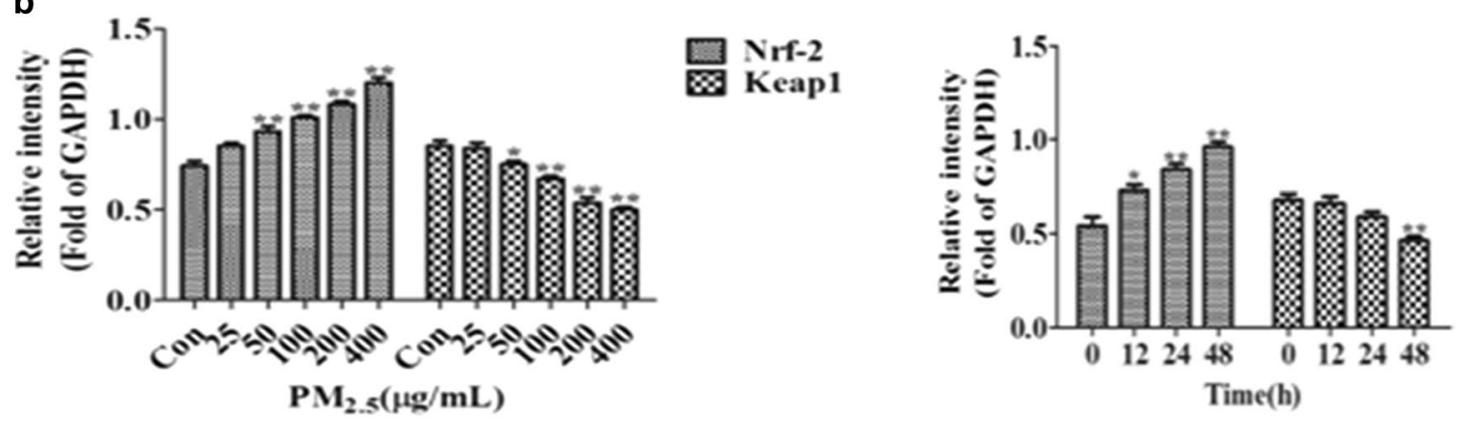

Nrf-2

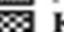

Keap1


Fig. 5 Activation of antioxidant pathway induced by $\mathrm{PM}_{2.5}$ in $\mathrm{HK}-2$ cells. a Cells were treated with the indicated concentrations of $\mathrm{PM}_{2.5}$ for $24 \mathrm{~h}$ (left) or PM $2.5(200 \mu \mathrm{g} / \mathrm{mL})$ for different durations (right), and the expression of the antioxidant-related proteins Nrf2, Keap1, HO-1 and NQO1 was analyzed using Western blot. $\mathbf{b}$ The intensity of the protein bands was quantified using ImageJ software and normalized to GAPDH. The data are expressed as mean \pm SD from three independent experiments. ${ }^{*} p<0.05$ and ${ }^{* *} p<0.01$ compared with the control group

was fourfold higher than those of the control group in SD rats induced by $\mathrm{PM}_{2.5}$ exposure during the early kidney injury [8]. Our present study showed that exposure to $\mathrm{PM}_{2.5}$ induced significant increases in the levels of KIM-1 in both a dose- and time-dependent manner, which is indicative of injury to the proximal tubule epithelium.

In our current study, we showed that $\mathrm{PM}_{2.5}$ treatment induced significant increases in ROS in a dose-dependent manner. Generation of ROS induced by $\mathrm{PM}_{2.5}$ has been reported in various cell lines [14, 41, 42]. Studies suggested that $\mathrm{PM}_{2.5}$ not only could directly induce the production of intracellular ROS by its inherent free radicals, organic chemicals and transition metals (such as $\mathrm{Mn}, \mathrm{Cu}$, $\mathrm{Vn}$ and $\mathrm{Fe}$ ), but also could indirectly increase the production of ROS from the inflammatory cells activated by $\mathrm{PM}_{2.5}$ [43]. Similarly, our results showed that $\mathrm{Al}, \mathrm{Mn}$, $\mathrm{Fe}$ and $\mathrm{Zn}$ were the most abundant elements, while we also detected the presence of toxic heavy metals, such as $\mathrm{Pb}, \mathrm{Cu}, \mathrm{Cd}, \mathrm{Cr}$ and $\mathrm{Ni}$, and $16 \mathrm{PAHs}$ in our $\mathrm{PM}_{2.5}$ samples. Therefore, we speculate that the chemical composition might play an important role in $\mathrm{PM}_{2.5}$ induced by an increased production of ROS in HK-2 cell. Overproduction of ROS may lead to severe damage to DNA and proteins and cause an imbalance in cell homeostasis, 



b
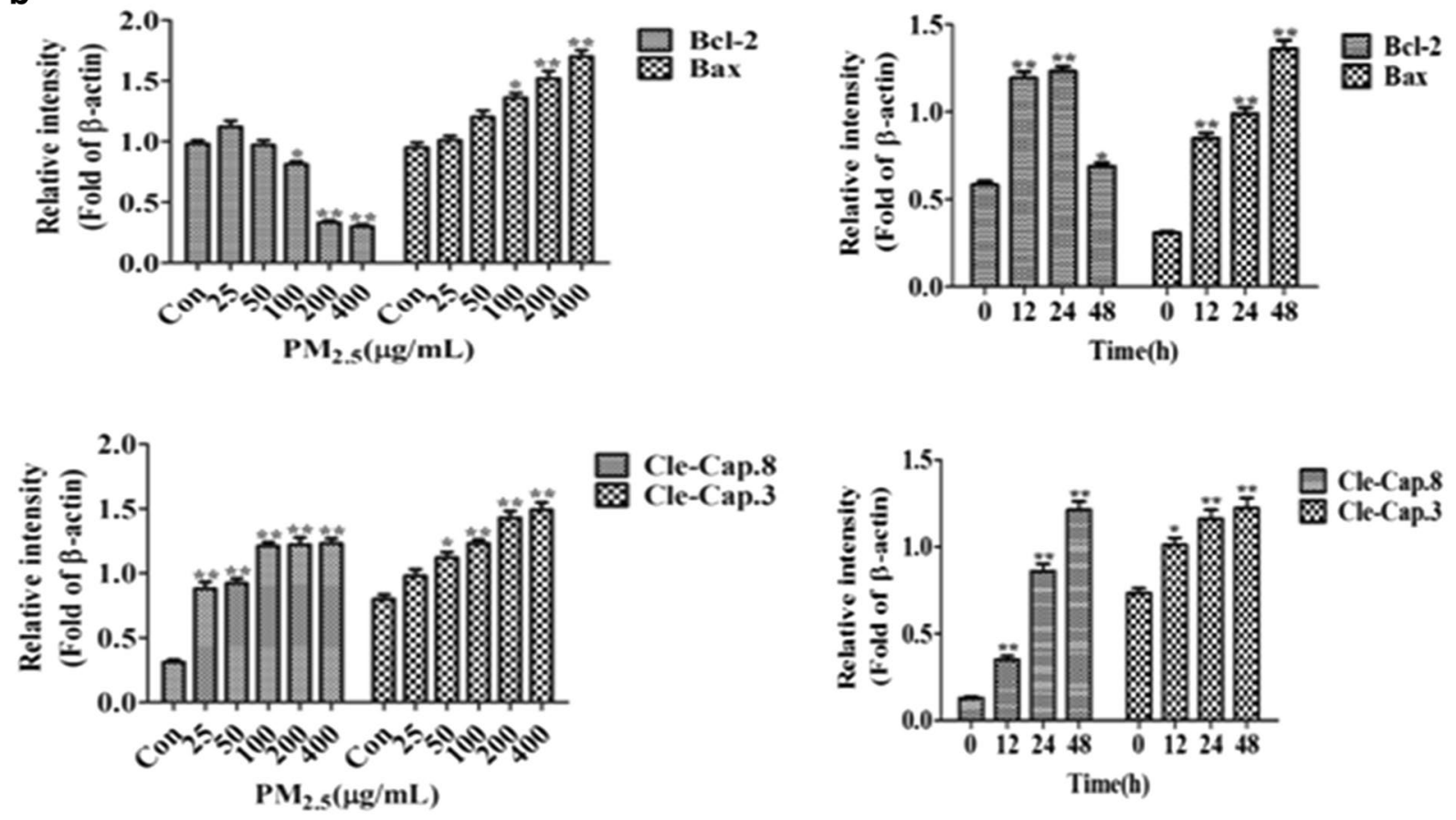

Fig. 6 Activation of apoptosis pathway induced by $\mathrm{PM}_{2.5}$ in HK-2 cells. a Cells were treated with the indicated concentrations of $\mathrm{PM}_{2.5}$ for $24 \mathrm{~h}$ (left) or $\mathrm{PM}_{2.5}(200 \mathrm{\mu g} / \mathrm{mL})$ at different time intervals (right) to examine the total protein expression of apoptosis-related proteins. b Intensity of protein bands was quantified using ImageJ software and normalized to $\beta$-actin. Data are expressed as mean \pm SD from three independent experiments. ${ }^{*} p<0.05$ and ${ }^{*} p<0.01$, compared with control group

resulting in autophagy, apoptosis and cell death [44]. Cells also need to increase the expression of antioxidant genes to maintain intracellular homeostasis against oxidative stress [4]. Deng et al. found that $\mathrm{PM}_{2.5}$-induced ROS could work as signaling molecules to activate Nrf2mediated defense pathway, such as HO-1 expression, against oxidative stress induced by $\mathrm{PM}_{2.5}$ in human lung alveolar epithelial A549 cells [19]. Our present study showed that $\mathrm{PM}_{2.5}$ exposure triggered the activation of the Nrf2/Keap1 signaling pathway, as evidenced by the significant increases in Nrf2, HO-1 and NQO1 protein expression and corresponding decreases in Keap1 protein expression, which occurred in a dose- and timedependent manner, indicating $\mathrm{PM}_{2.5}$ is able to activate Nrf2-mediated defense mechanisms to curb the adverse effects of oxidative stress caused by ROS. Many studies have demonstrated that Nrf2 signaling pathway played a key role in protection against stress, mainly via activation of multiple genes involved in antioxidant and detoxification pathways, including the phase II detoxification enzymes NQO1 and HO-1 $[45,46]$. Similarly, $\mathrm{PM}_{2.5}$ has been demonstrated to elevate the expression of $\mathrm{HO}-1$ 
and NQO1 in human lung epithelial cells (BEAS-2B) and human lung alveolar epithelial A549 cells [23, 39]. Our results indicated that $\mathrm{PM}_{2.5}$-induced oxidative stress can lead to renal toxicity.

Cell apoptosis, also known as programmed cell death, is a highly autonomic process that involves biochemical reactions and changes in cell characteristics [47]. Changes in early apoptotic morphology include cell shrinkage, cell membrane blebbing and chromosome concentration, and late apoptosis is characterized by the formation of apoptotic bodies and DNA fragmentation $[48,49]$. Similarly, we observed that a part of $\mathrm{PM}_{2.5}$-treated cells displayed apoptotic morphological changes in their nuclei, including formation of chromatin condensation and apoptotic bodies (Fig. 2a). Due to the toxic effects, $\mathrm{PM}_{2.5}$ can lead to the induction of apoptotic events by activating both the extrinsic pathway (caspase- 8 and caspase- 3 activation) and the intrinsic pathway (caspase-9 and caspase-3 activation) [27, 50]. The activation of intrinsic pathway is mainly linked to mitochondrial damage and loss of mitochondrial membrane potential [21]. In this study, mitochondrial membrane breach and cristae disorder were observed, along with the loss of MMP after $\mathrm{PM}_{2.5}$ exposure. Moreover, the total apoptotic rates (including early and late apoptosis) were clearly increased at elevating levels of $\mathrm{PM}_{2.5}$ treatment (Fig. 3). Apoptosis is controlled by a network of genes and plays a key role in cytotoxicity induced by exposure to harmful compounds such as $\mathrm{PM}_{2.5}[26,51]$. The Bcl-2 family includes numerous pro- and antiapoptotic members, and the balance in the expression of these proteins is one of the main mechanisms that determine the ultimate fate of cells. Our present study showed that exposure to $\mathrm{PM}_{25}$ caused a significant cytotoxicity and resulted in apoptosis of HK-2 cells in a dose-dependent manner along with activation of caspase- 3 , caspase- 8 and Bax/Bcl-2 (Fig. 6). These results demonstrate that the activation of apoptosis pathway mediated by $\mathrm{PM}_{2.5}$ is critically involved in $\mathrm{PM}_{2.5}$-induced renal toxicity.

\section{Conclusions}

Our study showed that $\mathrm{PM}_{2.5}$ within the dose range of the experiment $(25-400 \mu \mathrm{g} / \mathrm{mL})$ caused obvious cytotoxicity, oxidative stress and apoptosis in HK-2 cells. Antioxidant and apoptosis signaling pathways all play important biological roles following ambient $\mathrm{PM}_{2.5}$ exposure and can cause adverse or helpful effects on renal function; however, their exact "cross-talk" mechanism remains unclear. Further studies are required to investigate how these physiological and pathological mechanisms play a role in the renal toxicity induced by $\mathrm{PM}_{2.5}$, especially with regard to the individual organic and inorganic components of $\mathrm{PM}_{2.5}$. A multi-tiered prevention strategy is required to optimally protect public health in areas that have high $\mathrm{PM}_{2.5}$ concentrations, such as Shanghai.

\section{Abbreviations}

$\mathrm{PM}_{25}$ : fine particulate matter; HK-2: human proximal tubule epithelial cells; KIM-1: kidney injury molecule-1; Nrf2: nuclear factor erythroid-derived 2-like; Keap1: Kelch-like ECH-associated protein 1; MMP: mitochondrial membrane potential; LDH: lactate dehydrogenase; ROS: reactive oxygen species; $\mathrm{HO}-1$ : heme oxygenase-1; NQ01: NADPH: quinone oxidoreductase 1; PAHs: polycyclic aromatic hydrocarbons; cle-cap.8: cleaved caspase-8; cle-cap.3: cleaved caspase-3

\section{Acknowledgements}

We would like to thank Dr. Ying Liu for his help in the analysis of $\mathrm{PM}_{25}$ chemical compositions and Professor Andong Qiu for providing HK-2 cell line kindly.

\section{Authors' contributions}

$\mathrm{XH}$ was involved in the experiments, data processing and analysis, and manuscript writing. XK and JL designed the study and contributed to modification of the manuscript. XS and LZ were responsible for the guidance of the experiments. JZ, SL and $\mathrm{HZ}$ contributed to the collection and treatment of $\mathrm{PM}_{2.5}$ particles. All authors read and approved the final manuscript.

\section{Funding}

This research was supported by the Shanghai Key Laboratory of Meteorology and Health (Grant Nos.: QXJK201612 and QXJK201805).

\section{Availability of data and materials}

The datasets obtained and analyzed in the current study are available from the corresponding author on reasonable request.

Ethics approval and consent to participate

Not applicable.

\section{Consent for publication}

Not applicable.

\section{Competing interests}

The authors declare that they have no competing interests.

\section{Author details}

1 Shanghai East Hospital, Tongji University School of Medicine, Shanghai 200092, China. ${ }^{2}$ School of Medicine, Jinggangshan University, Ji'an 343009, Jiangxi, China. ${ }^{3}$ Institute of Clinical Epidemiology and Evidence-based Medicine, Tongji University School of Medicine, Shanghai 200092, China. ${ }^{4}$ Key Laboratory of Arrhythmia, Ministry of Education, East Hospital, Tongji University School of Medicine, Shanghai 200092, China. ${ }^{5}$ Shanghai Key Laboratory of Meteorology and Health, Shanghai Meteorological Service, Shanghai 200030, China. ${ }^{6}$ Department of Occupational Medicine, Yangpu Hospital, Tongji University, Shanghai 200092, China.

Received: 27 October 2019 Accepted: 29 December 2019 Published online: 16 January 2020

\section{References}

1. Li J, Liu H, Lv Z, Zhao R, Deng F, Wang C, Qin A et al (2018) Estimation of PM2.5 mortality burden in China with new exposure estimation and local concentration-response function. Environ Pollut 243:1710-1718

2. Chen $T$, Jin H, Wang H, Yao Y, Aniagu S, Tong J, Jiang Y (2019) Aryl hydrocarbon receptor mediates the cardiac developmental toxicity of EOM from PM2.5 in P19 embryonic carcinoma cells. Chemosphere 216:372-378

3. Coccini T, Barni S, Mustarelli P, Locatelli C, Roda E (2015) One-month persistence of inflammation and alteration of fibrotic marker and cytoskeletal proteins in rat kidney after Cd-doped silica nanoparticle instillation. Toxicol Lett 232:449-457 
4. Dong G-H (2017) Ambient air pollution and health impact in China, vol 1017. Springer, Singapore

5. Bowe B, Xie Y, Li T, Yan Y, Xian H, Al-Aly Z (2018) Particulate matter air pollution and the risk of incident CKD and progression to ESRD. J Am Soc Nephrol 29:218-230

6. Chen SY, Chu DC, Lee JH, Yang YR, Chan CC (2018) Traffic-related air pollution associated with chronic kidney disease among elderly residents in Taipei City. Environ Pollut 234:838-845

7. Mehta AJ, Zanobetti A, Bind MA, Kloog I, Koutrakis P, Sparrow D, Vokonas PS et al (2016) Long-term exposure to ambient fine particulate matter and renal function in older men: the veterans administration normative aging study. Environ Health Perspect 124:1353-1360

8. Aztatzi-Aguilar OG, Uribe-Ramirez M, Narvaez-Morales J, De Vizcaya-Ruiz A, Barbier O (2016) Early kidney damage induced by subchronic exposure to PM2.5 in rats. Part Fibre Toxicol 13:68

9. Chenxu G, Minxuan X, Yuting Q, Tingting G, Jinxiao L, Mingxing W, Sujun W et al (2018) iRhom2 loss alleviates renal injury in long-term PM2.5exposed mice by suppression of inflammation and oxidative stress. Redox Biol 19:147-157

10. Waly Ml, Ali BH, Nemmar A (2013) Acute effects of diesel exhaust particles and cisplatin on oxidative stress in cultured human kidney (HEK 293) cells, and the influence of curcumin thereon. Toxicol In Vitro 27:2299-2304

11. Liu J, Zhang J, Ren L, Wei J, Zhu Y, Duan J, Jing L et al (2019) Fine particulate matters induce apoptosis via the ATM/P53/CDK2 and mitochondria apoptosis pathway triggered by oxidative stress in rat and GC-2spd cell. Ecotoxicol Environ Saf 180:280-287

12. Ojeda AS, Ford SD, Gallucci RM, Ihnat MA, Philp RP (2019) Geochemical characterization and renal cell toxicity of water-soluble extracts from U.S. Gulf Coast lignite. Environ Geochem Health 41:1037-1053

13. Liu HH, Lin MH, Chan Cl, Chen HL (2010) Oxidative damage in foundry workers occupationally co-exposed to PAHs and metals. Int J Hyg Environ Health 213:93-98

14. Cao J, Qin G, Shi R, Bai F, Yang G, Zhang M, Lv J (2016) Overproduction of reactive oxygen species and activation of MAPKs are involved in apoptosis induced by PM25 in rat cardiac H9c2 cells. J Appl Toxicol 36:609-617

15. Li B, Guo L, Ku T, Chen M, Li G, Sang N (2018) PM2.5 exposure stimulates COX-2-mediated excitatory synaptic transmission via ROS-NF-kappaB pathway. Chemosphere 190:124-134

16. Chen X, Liu S, Zhang W, Wu C, Liu H, Zhang F, Lu Z et al (2018) Nrf2 deficiency exacerbates PM2.5-induced olfactory bulb injury. Biochem Biophys Res Commun 505:1154-1160

17. Saito H (2013) Toxico-pharmacological perspective of the Nrf2-Keap1 defense system against oxidative stress in kidney diseases. Biochem Pharmacol 85:865-872

18. Kim HJ, Vaziri ND (2010) Contribution of impaired Nrf2-Keap1 pathway to oxidative stress and inflammation in chronic renal failure. Am J Physiol Renal Physiol 298:F662-F671

19. Deng X, Rui W, Zhang F, Ding W (2013) PM25 induces Nrf2-mediated defense mechanisms against oxidative stress by activating PIK3/AKT signaling pathway in human lung alveolar epithelial A549 cells. Cell Biol Toxicol 29:143-157

20. Peixoto MS, de Oliveira Galvao MF, Batistuzzo de Medeiros SR (2017) Cell death pathways of particulate matter toxicity. Chemosphere 188:32-48

21. Yang X, Feng L, Zhang Y, Hu H, Shi Y, Liang S, Zhao T et al (2018) Cytotoxicity induced by fine particulate matter (PM2.5) via mitochondria-mediated apoptosis pathway in human cardiomyocytes. Ecotoxicol Environ Saf 161:198-207

22. Zhang J, Liu J, Ren L, Wei J, Duan J, Zhang L, Zhou X et al (2018) PM25 induces male reproductive toxicity via mitochondrial dysfunction, DNA damage and RIPK1 mediated apoptotic signaling pathway. Sci Total Environ 634:1435-1444

23. Zhou W, Yuan X, Zhang L, Su B, Tian D, Li Y, Zhao J et al (2017) Overexpression of HO-1 assisted PM2.5-induced apoptosis failure and autophagyrelated cell necrosis. Ecotoxicol Environ Saf 145:605-614

24. Eisenberg-Lerner A, Bialik S, Simon HU, Kimchi A (2009) Life and death partners: apoptosis, autophagy and the cross-talk between them. Cell Death Differ 16:966-975

25. Singh R, Letai A, Sarosiek K (2019) Regulation of apoptosis in health and disease: the balancing act of BCL-2 family proteins. Nat Rev Mol Cell Biol 20:175-193
26. Dagher Z, Garcon G, Billet S, Gosset P, Ledoux F, Courcot D, Aboukais A et al (2006) Activation of different pathways of apoptosis by air pollution particulate matter (PM2.5) in human epithelial lung cells (L132) in culture. Toxicology 225:12-24

27. Deng X, Zhang F, Wang L, Rui W, Long F, Zhao Y, Chen D et al (2014) Airborne fine particulate matter induces multiple cell death pathways in human lung epithelial cells. Apoptosis 19:1099-1112

28. Gao L, Wu WF, Dong L, Ren GL, Li HD, Yang Q, Li XF et al (2016) Protocatechuic aldehyde attenuates cisplatin-induced acute kidney injury by suppressing Nox-mediated oxidative stress and renal inflammation. Front Pharmacol 7:479

29. Jiang M, Zhang H, Zhai L, Ye B, Cheng Y, Zhai C (2017) ALA/LA ameliorates glucose toxicity on HK-2 cells by attenuating oxidative stress and apoptosis through the ROS/p38/TGF-beta1 pathway. Lipids Health Dis 16:216

30. Arbillaga L, Azqueta A, Ezpeleta O, Lopez de Cerain A (2007) Oxidative DNA damage induced by Ochratoxin A in the HK-2 human kidney cell line: evidence of the relationship with cytotoxicity. Mutagenesis 22:35-42

31. Hauschke M, Rousarova E, Flidr P, Capek J, Libra A, Rousar T (2017) Neutrophil gelatinase-associated lipocalin production negatively correlates with HK-2 cell impairment: evaluation of NGAL as a marker of toxicity in HK-2 cells. Toxicol In Vitro 39:52-57

32. Racusen LC, Monteil C, Sgrinoli A, Lucskay M, Marouillat S, Rhim JG, Morin JP (1997) Cell lines with extended in vitro growth potential from human renal proximal tubule: characterization, response to inducers, and comparison with established cell lines. J Lab Clin Med 129:318-329

33. Yang X, Liu L, Wang S (2019) A strategy of high-efficient nitrogen removal by an ammonia-oxidizing bacterium consortium. Bioresour Technol 275:216-224

34. Zhao Z, Lv S, Zhang Y, Zhao Q, Shen L, Xu S, Yu J et al (2019) Characteristics and source apportionment of PM2.5 in Jiaxing, China. Environ Sci Pollut Res Int 26:7497-7511

35. Liu Y, Yu Y, Liu M, Lu M, Ge R, Li S, Liu X et al (2018) Characterization and source identification of PM2.5-bound polycyclic aromatic hydrocarbons $(\mathrm{PAHs})$ in different seasons from Shanghai, China. Sci Total Environ 644:725-735

36. Wang Q, Liu M, Li Y, Liu Y, Li S, Ge R (2016) Dry and wet deposition of polycyclic aromatic hydrocarbons and comparison with typical media in urban system of Shanghai, China. Atmos Environ 144:175-181

37. Lee YS, Kim DW, Lee YH, Oh JH, Yoon S, Choi MS, Lee SK et al (2011) Silver nanoparticles induce apoptosis and G2/M arrest via PKCzeta-dependent signaling in A549 lung cells. Arch Toxicol 85:1529-1540

38. Rui W, Guan L, Zhang F, Zhang W, Ding W (2016) PM2.5-induced oxidative stress increases adhesion molecules expression in human endothelial cells through the ERK/AKT/NF-kappaB-dependent pathway. J Appl Toxicol 36:48-59

39. Deng X, Zhang F, Rui W, Long F, Wang L, Feng Z, Chen D et al (2013) PM2.5-induced oxidative stress triggers autophagy in human lung epithelial A549 cells. Toxicol In Vitro 27:1762-1770

40. Moresco RN, Bochi GV, Stein CS, De Carvalho JAM, Cembranel BM, Bollick YS (2018) Urinary kidney injury molecule-1 in renal disease. Clin Chim Acta 487:15-21

41. Feng L, Yang X, Asweto CO, Wu J, Zhang Y, Hu H, Shi Y et al (2017) Lowdose combined exposure of nanoparticles and heavy metal compared with PM2.5 in human myocardial AC16 cells. Environ Sci Pollut Res Int 24:27767-27777

42. Yang J, Huo T, Zhang X, Ma J, Wang Y, Dong F, Deng J (2018) Oxidative stress and cell cycle arrest induced by short-term exposure to dustfall PM25 in A549 cells. Environ Sci Pollut Res Int 25:22408-22419

43. Feng S, Gao D, Liao F, Zhou F, Wang X (2016) The health effects of ambient PM2.5 and potential mechanisms. Ecotoxicol Environ Saf 128:67-74

44. Fetoni AR, Paciello F, Rolesi R, Paludetti G, Troiani D (2019) Targeting dysregulation of redox homeostasis in noise-induced hearing loss: oxidative stress and ROS signaling. Free Radic Biol Med 135:46-59

45. Zhang H, Xue L, Li B, Tian H, Zhang Z, Tao S (2018) Therapeutic potential of bixin in PM2.5 particles-induced lung injury in an Nrf2-dependent manner. Free Radic Biol Med 126:166-176

46. Mondal NK, Saha H, Mukherjee B, Tyagi N, Ray MR (2018) Inflammation, oxidative stress, and higher expression levels of $\mathrm{Nrf} 2$ and NQO1 proteins in the airways of women chronically exposed to biomass fuel smoke. Mol Cell Biochem 447:63-76 
47. Gilmore A, King L (2019) Emerging approaches to target mitochondrial apoptosis in cancer cells. F1000Research 8

48. Povea-Cabello S, Oropesa-Avila M, de la Cruz-Ojeda P, Villanueva-Paz M, de la Mata M, Suarez-Rivero JM, Alvarez-Cordoba M et al (2017) Dynamic reorganization of the cytoskeleton during apoptosis: the two coffins hypothesis. Int J Mol Sci 18:2393

49. Collins JA, Schandl CA, Young KK, Vesely J, Willingham MC (1997) Major DNA fragmentation is a late event in apoptosis. J Histochem Cytochem 45:923-934

50. Wang W, Deng Z, Feng Y, Liao F, Zhou F, Feng S, Wang X (2017) PM2.5 induced apoptosis in endothelial cell through the activation of the p53-bax-caspase pathway. Chemosphere 177:135-143
51. Liu L, Li T, Tan J, Fu J, Guo Q, Ji H, Zhang Y (2014) NG as a novel nitric oxide donor induces apoptosis by increasing reactive oxygen species and inhibiting mitochondrial function in MGC803 cells. Int Immunopharmacol 23:27-36

\section{Publisher's Note}

Springer Nature remains neutral with regard to jurisdictional claims in published maps and institutional affiliations.

\section{Submit your manuscript to a SpringerOpen ${ }^{\circ}$ journal and benefit from:}

- Convenient online submission

- Rigorous peer review

- Open access: articles freely available online

- High visibility within the field

- Retaining the copyright to your article

Submit your next manuscript at $\boldsymbol{\nabla}$ springeropen.com 